Contents list available at IJRED website

Int. Journal of Renewable Energy Development (IJRED)

Journal homepage: www.ijred.com

\title{
Power Quality Improvement Wind Energy System Using Cascaded Multilevel Inverter
}

\author{
J.S. Sathiyanarayanan*a, and A. S. Kumarb \\ a Dept.of EEE Arunai College of Engineering ,Velu Nagar Tiruvannamalai, Tamilnadu, INDIA \\ ${ }^{b}$ Dept.of EEE Velammal Engineering College Chennai, Tamilnadu. INDIA
}

\section{Article history:}

Received Dec 12, 2012 Received in revised form Jan 8, 2012 Accepted Jan 15, 2013 Available online

\begin{abstract}
In this paper, a wind energy conversion system based on a cascaded H-bridge multilevel inverter (CHBMLI) topology has been proposed to be used for the grid interface of large split winding alternators (SWAs). A new method has been suggested for the generation of reference currents for the voltage source inverter (VSI) depending upon the available wind power. The CHBMLI has been used as a VSI and operated in a current control mode order to achieve the objectives of real power injection and load compensation (power factor correction, load balancing, and harmonic compensation) based on the proposed reference generation scheme. In the field excitation control of SWA provides a single means vary the dc link voltages of all the CHBs simultaneously and proportionately.
\end{abstract}

Keywords : Power quality, Multilevel inverter, Power factor, Split winding alternator

\section{Introduction}

The current trend in wind turbines is to increase the size of the turbine in order to harvest more energy and thus reduce cost per megawatt of capacity. Power ratings of 3-5 MW per machine are becoming common in areas with large wind potentials, especially offshore wind installations (ABB Product Catalogue 2009; Steinke \& Apeldoorn 2002). The major problem in interfacing such machines to the grid is the limitation imposed by the ratings of currently available switching devices in the converter. The ratings of the semiconductor devices used in the conventional two level or three level VSI topologies do not support the higher power ratings necessary for the grid interface such large machines.

This has motivated designers to go for medium voltage converters as these are more compact than low voltage converters for power larger than 1.5 MW (Faulstich et al. 2005; Rodriguez et al. 2002). The use of multilevel VSI topology for distributing voltage stress and power losses between a numbers of devices has been well reported (Carrasco et al. 2006; Erickson et al.
2004) and the multilevel inverters are suitable for modern high power wind turbine applications (Krug et al. 2007). Due to the great demand of medium voltage high power converters in industry, the cascade H-bridge multilevel inverter (CHBMLI) has drawn tremendous interest ever since its inception. Five levels CHBMLI is very common in industrial medium voltage drives applications (Slootweg et al. 2003; Ullah et al. 2009). This converter topology is based on the series connection of single-phase $\mathrm{H}$-bridge cells with separate dc sources. It requires the least number of components and is known to eliminate the excessively large number of bulky transformers required by the multi pulse inverters, clamping diodes required by the diodeclamped multilevel inverters (DCMLIs), and additional capacitors required by the flying capacitor multilevel inverters (FCMLIs). The CHBMLI topology with equal dc link voltages for each $\mathrm{H}$-bridge cells and fixed switching frequency will be able to provide equal switching stress and power handling for all the CHB cells. Traditionally, wind turbines have been operated only as energy sources and have not been expected to provide grid support functions like voltage support, frequency

\footnotetext{
* Corresponding author:

E-mail: jssathya@gmail.com
} 
control, fault ride through, and spinning reserve, but as the penetration of wind in the overall generation maximum increased (Brekken \& Mohan 2003; Brekken \& Mohan 2007). In addition, control of doubly fed induction generator for compensating torque pulsation under unbalanced supply voltage has also been investigated and reported in (Singh et al. 2007; D'iazDorado et al. 2008; Tenca et al. 2007). In addition, when located close to load centers as considered in this paper, and connected to the distribution system, they may be even required to perform harmonic compensation. It has been earlier suggested to use split-winding alternators (SWAs) for electrical vehicle drive systems for synchronous reluctance machines and for obtaining higher phase-order induction machines. Recently, multiple-pole permanent magnet alternators (PMAs) have been suggested for the grid interface of the wind power through five level cascaded multilevel inverters using power electronics building blocks (PEBBs) (Erickson et al. 2004). Each PEBB in this application consists of a rectifier, a dc link, and an H-bridge cell. The split windings in the three phases produce ac voltages with equal peak values that rectified and used as independent and isolated dc sources for the CHB cells of the multilevel inverter. With PMA, the independent control of terminal voltage is not possible as the main field is setup by permanent magnets. A conventional synchronous generator with external excitation has the capability of terminal voltage control and hence gives additional control over dc-link voltages. Additionally, splitting of the windings of the alternator in equal number of parts in each phase helps in reducing the voltage and power ratings of the $3(n-1) / 2$ numbers of PEBBs for an n-level inverter. In particular, for a threephase seven-level inverter using three split windings per phase of an alternator, total nine such units are required. Since all the dc sources feeding the CHBMLI are equal in magnitude, an equal voltage CHBMLI can be appropriately used to equally distribute losses among the different switching devices. This is achieved by using a constant switching frequency for all the CHB cells. The symmetry involved in SWA with equal voltages obtained at the output suits the modular structure of H-bridges in the cascaded multilevel inverter (Abolhassani et al. 2008). Recently, it has been suggested that wind In this paper, a CHB multilevel inverter has been proposed with an SWA in order to interface the high power available from a large wind turbine to the grid. A new method has been suggested for the generation of reference currents for the voltage source inverter (VSI), depending upon the available wind power.

\section{Proposed Wind Energy Conversion System (Wecs) Using Split-Winding Alternator}

In this paper, a variable - speed wind turbine has been proposed as it can achieve a larger yearly energy yield as compared to a fixed speed wind turbine (Erickson et al. 2004). Since these turbines make a better utilization of the investment, all modern large wind energy systems above 2 MW now use variable speed turbines (Rodriguez et al. 2002; Faulstich et al. 2005). The single-line diagram for a conventional synchronous generator with fully rated converter-based WECS is shown in Fig. 1. Here, a three-phase alternator coupled to a large wind turbine is connected first to a three-phase uncontrolled diode bridge rectifier (DBR) followed by a dc-dc converter for dc voltage regulation. The fixed dc output is then interfaced to the grid through a conventional two-level dc-ac converter (Rodriguez et al. 2002; Erickson et al. 2004).

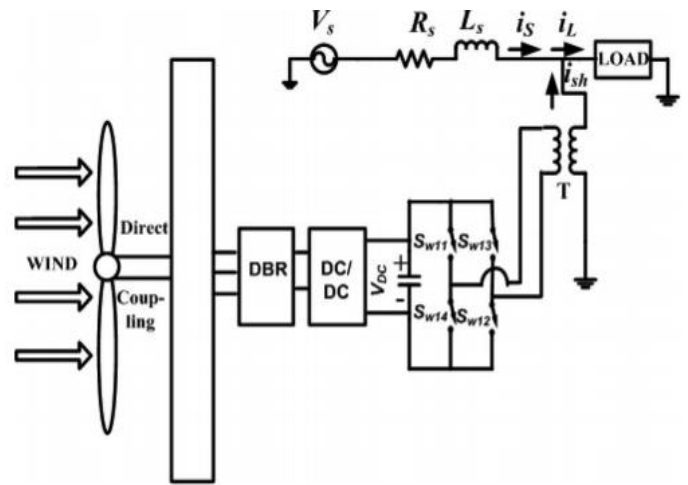

Fig. 1 Conventional synchronous generator-based WECS with fully rated converter.

Transfer of high power through this arrangement has to be at high voltage or current, and hence leads to higher thermal stress on the power semiconductor switching devices used. This requires the use of devices and components with higher power handling capability. Additional problems are that of current sharing and difficulty in loss distribution among the many switches, which might have to be used in series or parallel in order to handle large voltages or currents. In addition, it also produces an output, which has higher low order harmonic contents. Use of additional switches in the form of CHB cells resulting in CHBMLI has been considered as a better option as it eliminates the lower order harmonics, and produces a better quality output and performance in addition to reduced ratings for the switches. In particular, a seven-level converter topology alongside an SWA has been suggested in this paper. The proposed wind energy conversion system (WECS) 


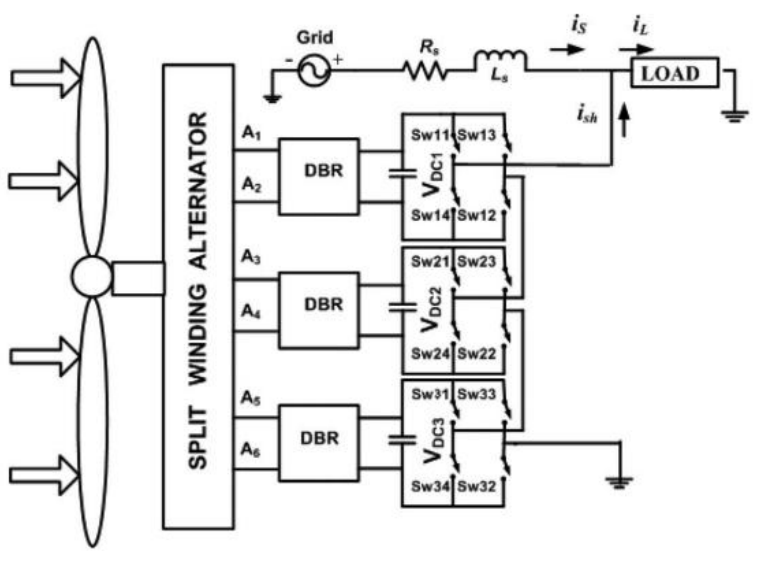

Fig. 2 Proposed SWA and cascaded multilevel inverter connections

consists of the wind turbine, SWA, and the ac/dc/ac conversion system, as shown in Fig. 2. The switches used S11, S12.........S34 shown in this figure are insulated gate bipolar transistors (IGBTs) with antiparallel diodes. A brief description of each element of the system is given in the following.

\subsection{Split-Winding Alternator}

A synchronous generator has been proposed for this application with each phase split into three windings having equal number of turns and equal current ratings. Since the three split windings in each phase are electrically isolated from each other, they can be used to feed three separate rectifiers and thus can form three isolated dc sources for each phase of the CHBMLI. Since the peak values of the ac voltages of each of the nine split windings are equal, for balanced load condition, the dc-link voltages for all cells will be equal. The alternator will operate within its rated duty if the individual winding voltages and currents are restricted to their rated limits and the three-phase loads on the ac side are kept balanced. Fig. 3 shows the stator of a split winding three-phase alternator with three split windings per phase. Each of the three phases have been split into three equally rated windings and all the six terminals per phase (total eighteen terminals for all the three phases of the stator) have been brought out so that they can be connected independently to nine DBRs. The field winding is on the rotor and is supplied through two slip rings as usual.

\subsection{Generation of Reference Currents and Fast Current Control of the CHBMLI}

The second control loop, i.e., the instantaneous current control loop implemented in the CHBMLI is used to inject a component of current corresponding to the real power injection together with the load compensation current component to offset the harmonic, reactive, and unbalance components of the load current. For achieving this, reference currents have

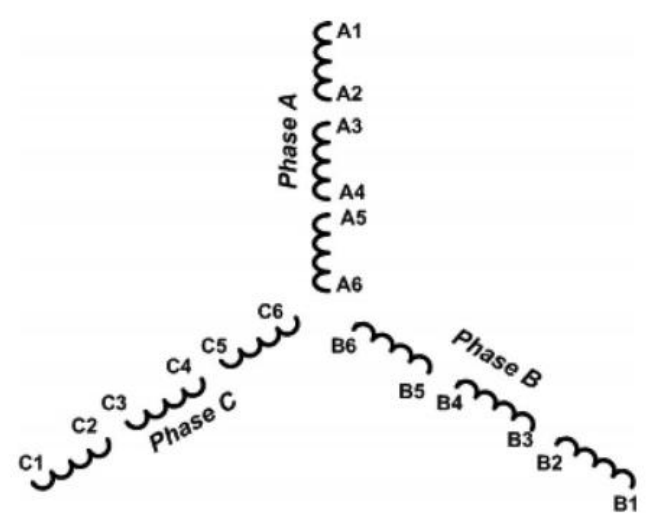

Fig. 3 Stator of an SWA with three split windings per phase.

to be generated for each phase and these currents must be tracked using the closed loop multicarrier PWM algorithm (Brekken \& Mohan 2007). The power from the wind turbine pwind can be computed using the value of wind speed measured by a wind speed sensor or estimated by using the following:

$$
p_{\text {wind }}=\frac{1}{2} \rho A C_{p} V_{w}^{3}
$$

where $A$ is the wind-turbine rotor swept area in square meter, VW is the speed of the wind in meter per second, $\mathrm{Cp}$ is the power co efficient, and $\rho$ is the air density in kilograms per cubic meter. It may be noted that there is a time delay for the changed wind power level to be reflected in the generator because of the large turbine inertia. Hence, an appropriate time delay may be incorporated in the computation or estimation of equivalent available power using (3) for reference current generation.

$$
C_{\text {max }}=0.59
$$

In most of the cases, the wind turbine is operated at the maximum power point under the prevalent wind conditions and the value of the maximum power can be estimated using any of the maximum power point tracking (MPPT) techniques like TSR control and power signal feedback (PSF) control.

$$
\lambda(\max \text { power })=\mathrm{n} / 4 \Pi
$$

In the former case, the rotor speed and wind speed measurement/estimation have to be done in order to calculate the TSR $\lambda$ and run the machine at the optimum $\lambda$, whereas in the latter case, the rotor speed measurement has to be done in order to select the stored speed power curve, which gives the target optimum power to be tracked by the system. In case the TSR technique of MPPT is used, the maximum available power from the wind turbine $\mathrm{p}$ can be obtained using optimum value of $\mathrm{C} \mathrm{P}_{\text {wind }}$ in (3). The proposed current reference-generation scheme is now discussed.

A three-phase four-wire compensated distribution system is shown in Fig. 4. The three-phase load currents 
may be unbalanced and consist of both linear and nonlinear elements, thus resulting in unbalanced and distorted PCC voltages. It is assumed that the compensator is lossless and comprises three ideal current sources and they are controlled by three VSIs, respectively.

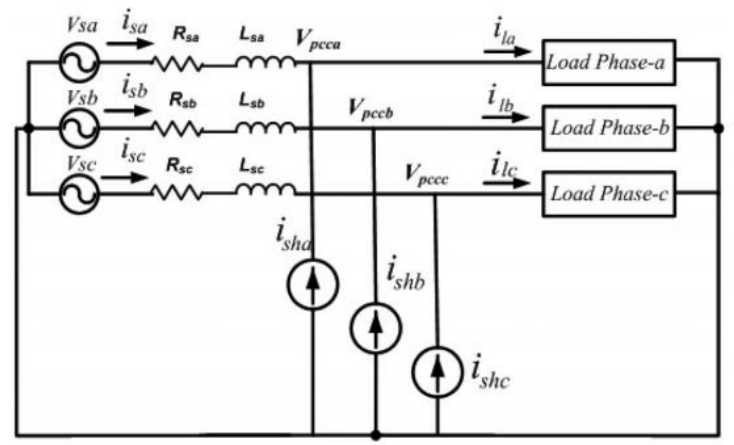

Fig. 4 Schematic diagram for real power injected and loadcompensated distribution system.

The three-phase shunt reference currents (isha, ishb, ishc) are generated from the measurements of the PCC or terminal voltages (VPCCa,VPCCb, and VPCCc) and load currents(ila ,ilb, and ilc). The source voltages and source currents are represented by (vsa,vsb, and vsc) and (isa, isb, and isc), respectively, in the three phases.Three conditions need to be satisfied in order to meet the requirements of load compensation. They are as follows.

1) Assuming perfect compensation, the zero sequence component of the source currents will be zero, i.e.,

$i_{s a}+i_{s b}+i_{s c}=0$

2) The reactive power delivered from the source is controlled by the phase angle between the positive sequence voltage VPCCa1 and positive sequence current $i_{\mathrm{sa} 1}$. This results in the following relationship:

$<$ VPCCa $1=<\mathrm{i}_{\mathrm{sa} 1}+\varphi$

Where $\varphi$ is the phase angle between the voltage VPCCa1 and the current isa1. For unity power factor, the combined load and compensator system draw a current from the source in-phase with the PCC voltage and therefore $\varphi=0$. Using instantaneous positive sequence components, (5)

Can be rewritten for unity power factor $(\varphi=0)$ as follows:

$$
\begin{aligned}
& \angle\left\{\mathrm{VPCCa}+\alpha \mathrm{VPCCb}+\alpha^{2} \text { VPCCc }\right\}= \\
& \angle\left\{\mathrm{i}_{\mathrm{sa}+} \alpha \mathrm{i}_{\mathrm{sb}+} \alpha^{2} \mathrm{i}_{\mathrm{sc}}\right\}
\end{aligned}
$$

where $\alpha=e^{i(2 \Pi / 3)}$, and the following can be written after substituting the value of $\alpha$ and $\alpha^{2}$ in (6)

$$
\begin{aligned}
& \left(v p c c_{a}-\frac{1}{2} v p c c_{b}-\frac{1}{2} v p c c_{c}\right)\left(i_{s b}-i_{s c}\right)= \\
& \left(i_{s a}-\frac{1}{2} i_{s b}-\frac{1}{2} i_{s c}\right)\left(v p c c_{b}-v p c c_{c}\right)
\end{aligned}
$$

Simplifying (7)

$$
\begin{aligned}
& \left(v p c c_{b}-v p c c_{c}\right) i_{s a}+\left(v p c c_{c}-v p c c_{a}\right) i_{s b}+ \\
& \left(v p c c_{a}-v p c c_{b}\right) i_{s c}=0
\end{aligned}
$$

3) The source should supply only the required active power( $p$ active), which is given by

$$
\operatorname{vpcc}_{a} i_{s a}+v p c c_{b} i_{s b}+v p c c_{c} i_{s c}=p_{a c t i v e}
$$

Since the VSI is also injecting a real power corresponding to the computed/estimated wind power ( $p_{\text {wind }}$ ) using (3), therefore the source should supply only the balance power, in the required active power pactive (9)

$p_{\text {active }}=p_{\text {lav }}-p_{\text {wind }}$

where plav is the average load power that is obtained by a moving average filter using the continuous measurement of instantaneous power that is given by

$$
p_{l}=v p c c_{a} i_{l a}+v p c c_{b} i_{l b}+v p c c_{c} i_{l c}
$$

Assuming that the VSI will track the reference shunt currents, the following expression can be written for the reference shunt currents in three phases:

$i_{s h \mathrm{kref}}=i_{l k}-i_{s k} \quad$ where $\mathrm{k}=a, b, c$

Combining (4)-(12) and using the following condition

$\frac{v p c c_{a}+v p c c_{a}+v p c c_{c}}{3}=v_{0}$

Where $\mathrm{v}_{0}$ is the zero-sequence voltage at the PCC, the expressions for generation of the reference current for three phases of the shunt converter can be obtained as follows:

$$
\left.\begin{array}{l}
i_{\text {sharef }}=i_{l a}-i_{\text {sharef }}=i_{l a}-\frac{\left(v p c c_{a}-v_{0}\right)}{\Delta}\left(p_{\text {lav }}-p_{\text {wind }}\right) \\
i_{\text {shbref }}=i_{l b}-i_{\text {shbref }}=i_{l b}-\frac{\left(v p c c_{b}-v_{0}\right)}{\Delta}\left(p_{\text {lav }}-p_{\text {wind }}\right) \\
i_{\text {shcref }}=i_{l c}-i_{\text {shcref }}=i_{l c}-\frac{\left(v p c c_{c}-v_{0}\right)}{\Delta}\left(p_{\text {lav }}-p_{\text {wind }}\right)
\end{array}\right\}
$$

Where $\Delta=v^{2} p c c_{a}+v^{2} p c c_{b}+v^{2} p c c_{c}-3 v_{0}^{2}$ $\mathrm{P}_{\text {wind }}$ maximum turbine power computed using the optimum value of power coefficient $C$ in (3) 


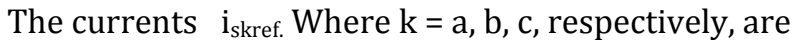
the reference shunt currents and the reference source Currents for the three phases. The voltage v0 $=0$ in (14), in case the PCC terminal voltages are balanced.

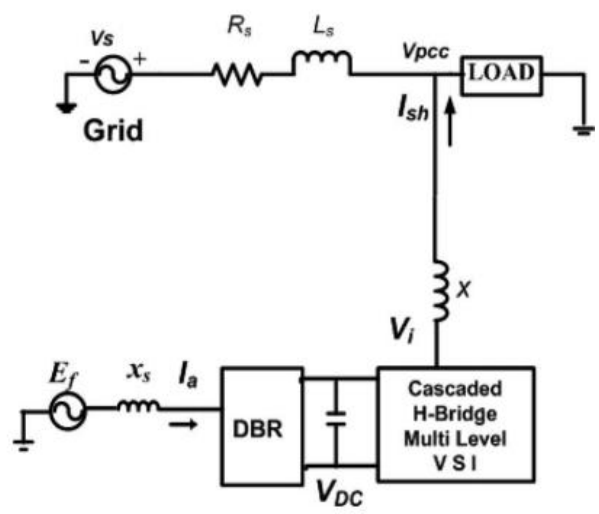

Fig. 5 Power flow diagram for the WECS.

The reference shunt current (14) will inject the real component of the current corresponding to the equivalent real power available from the wind turbine, in addition to the reactive, harmonic, and unbalanced components of the load using closedloop multicarrier PWM method discussed. As a result of this, the source currents drawn from the grid are balanced, sinusoidal, and in phase with the PCC voltage. In addition, the real power injected at the PCC takes up part or whole of the load as maybe the case, depending upon the wind power generated and the net excess power produced if any is exported to the grid. The single line diagram in Fig.5. shows the power flow between the CHBMLI fed by the SWA-DBR-VSI block and the PCC. If the reactance of the line and external filter reactor connected in between the VSI and PCC is assumed to be X, therms phase to neutral voltage at the PCC is assumed to be $V$, the rms phase to neutral voltage of the VSI is assumed to be V, and the rms shunt current injected into the PCC by the VSI is Ish ; then, the power transfer equations for the link connecting the VSI to the PCC are given as

$$
\overline{I_{s h}}=\frac{\overline{V_{i}}-\overline{V p c c}}{j X}
$$

Where $I_{s h}, V_{i}$ and $V_{P C C}$ are the injected current, inverter voltage, and PCC voltage phasors.

$$
P=3 \frac{V p c c V_{i} \sin \delta}{X}=3 \frac{V p c c M_{i} V_{d c} \sin \delta}{\sqrt{2} X}
$$

From the above, it is clear that since the PCC voltage $\mathrm{V}$ and link reactance $\mathrm{X}$ are constant, the three-phase real power flow between the VSI (CHBMLI) and PCC is proportional to the modulation index $\mathrm{Mi}$, dc-link voltage $\mathrm{V}$, and sine of the power angle $\delta$ between the voltages Vi and Vpcc. Since we `are using the three VSIs in current control mode, the controller basically injects three currents according to the three references generated in (11). The maximum value of real power is given by

$$
P_{\max }=3 \frac{V p c c M_{i} V_{d c}}{\sqrt{2} X}
$$

$\mathrm{P}_{\max }$ is decided by $\mathrm{V}$. The mechanical power input to the turbine in case of conventional energy sources can be controlled and hence the prime mover input power is continuously controlled by inlet valve/governor control, etc., in order to match the variable load power. However, in case the of wind turbines, the energy/power source is not controllable and hence the operating strategy is to match the load power to the generated power at all instants while operating in the safe wind speed limits. In the case of grid connected WECS, the power produced is injected into the grid assuming that it can absorb all the power produced by the wind turbine. The strategy proposed in this paper easily satisfies the aforementioned condition using (14). When the load power required is more than the power produced by the WECS, the remaining power is supplied by the grid. In case of excess power produced by the WECS than required by the load, the balance power will be injected into the grid.The reactive power $Q$ is given by

$$
Q=3 \frac{V_{i} V p c c}{X} \cos \delta-3 \frac{V^{2} p c c}{X}=3 \frac{V p c c M_{i} V_{d c}}{\sqrt{2} X} \cos \delta-3 \frac{V^{2} p c c}{X}
$$

The reactive power flow is decided by the variable Mi and Vdc. Thus, for fixed V, the reactive power flow can be controlled by control of the VSI output voltage by controlling $\mathrm{M} \mathrm{dc}$. In case the demand for reactive power exceeds the maximum injected at $\mathrm{M} \mathrm{I}=1$, the dc-link voltage $\mathrm{V}$ can be increased by controlling the reference of the excitation voltage using (2). Dc As a result of compensation using the proposed scheme, the source current becomes sinusoidal, in-phase with the PCC voltage, and perfectly balanced. Accordingly, the PCC voltage quality is also improved and the magnitude is also boosted as a good part of the load power is fed from the local WECS (distributed generation) rather than being imported via the weak link from the grid. The grid is relieved of feeding distant loads thus avoiding line losses and voltage drop. The wind-turbine alternator is free to operate at close to unity power factor as reactive power injection is done by the VSI, which results in optimum use of the alternator. The only flip side is that the VSI will have to be sized to handle the reactive and harmonic power demand of the load in addition to the real power output of the alternator.

\section{Simulation Results}

The parameters of the system that have been used for simulation. A $6.6-\mathrm{kV}$ four wire distribution system 
has been considered. It is desired to use commonly available IGBTs rated about $2.5 \mathrm{kV}$. Using a seven-level inverter with three $\mathrm{H}$ bridges, as shown in Fig. 2, fulfills this requirement. The dc-link voltage across each $\mathrm{H}$ bridge is around $2.2 \mathrm{kV}$ ( $\max$ ). The changes in the wind power pwind are assumed to be instantaneous as a worst-case situation in (14). In actual, these changes due to wind speed will take place slowly because of rotor inertia and mechanical time constants. The simulations shown in this paper are considered in a short time frame as per power system dynamics, in which it is assumed that the machine speed is constant for the period of consideration and the generator is modeled as a voltage source to verify the reference generation and control method proposed in this paper.

Case I: studies the effect of the wind turbine supported VSI on the PCC voltages and source currents, and the effect of the VSI on sharing of the load power between the grid and wind turbine.

Case 2: studies the performance of the converter during a step change in the reactive load. It shows that the increase in dc-link voltages using field excitation control of the alternator improves the converter capability to track the higher reference currents due to increase in the reactive component of the load.

\section{A. Case 1}

For this case, a combination of linear unbalanced load and nonlinear load is connected to the PCC and the VSI is switched on at time $\mathrm{t}=0.06 \mathrm{~s}$. The reference for the VSI is generated using (14) and controlled using the closed-loop multicarrier modulation discussed in Section II-D with the carrier frequency of $1 \mathrm{kHz}$. Fig. 6(a) shows the seven-level cascaded output of the VSI, whereas Fig. 6(b) shows the three-phase load and source currents before and after the VSI has been switched on to the PCC. It has been shown in Fig. 6(b) and (c) that due to presence of nonlinear loads, the source currents and PCC voltages get distorted, and as soon as the VSI is switched to the PCC, the voltages become close to sinusoidal and source currents become balanced, sinusoidal, and in-phase with the PCC voltage. This indicates that all the harmonic, reactive, and unbalanced currents are fed from the VSI connected in shunt, and the source is relieved of supplying these components and only supplies the real part of the load. This also improves the PCC voltage. As shown in Fig. $6(d)$, the power available from the wind turbine is injected into the PCC after the VSI is switched on, and as a result, the power coming from the source is reduced from 0.95 to $0.24 \mathrm{MW}$. Since the PCC voltage is improved both in quantity and quality, the load power also increases from 0.95 to $1.22 \mathrm{MW}$. The contribution of wind to this load power is approximately $1.05 \mathrm{MW}$. It is also observed that THD of the source current is improved from $8.3 \%$ to $2.5 \%$. The use of PS-PWM eliminates the switching harmonics components up to 6 $\mathrm{kHz}$ for a carrier frequency of $1 \mathrm{kHz}$ and along with the compensated source current improves the waveform of the PCC voltage close to sinusoidal. Fig. 6(e) shows the relationship between PCC voltage and source current in phase A before and after switching on the VSI. It is clearly seen that the source currents that were lagging and non sinusoidal earlier are now in phase with the PCC with sinusoidal wave shape. Fig. 6(f) shows the reference shunt current tracking by the VSI for phase A in order to transfer real power and also provide load compensation. Tracking characteristics for the phases $\mathrm{B}$ and $C$ are also similar. Fig. $6(\mathrm{~g})$ shows that all the nine split winding voltages are equal and Fig. 6(h) shows that the nine dc-link voltages from the nine DBRs are also equal in magnitude. All the nine dc-link voltages can be controlled by setting the terminal voltage set point of the excitation controller using (2).

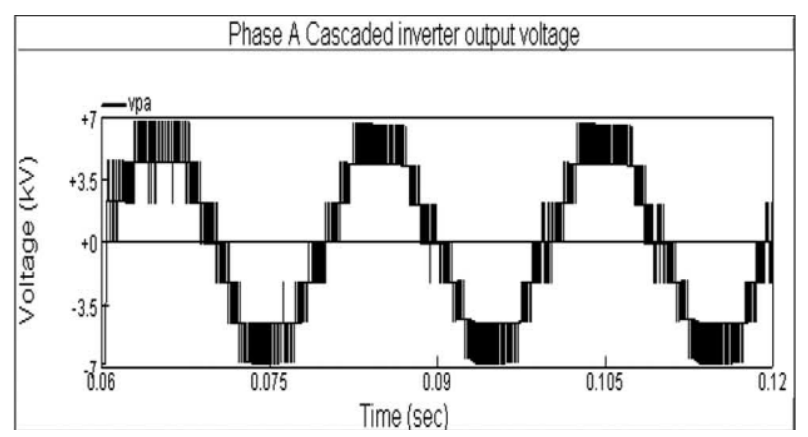

Fig. 6 (a) Cascaded seven-level inverter output for phase A.
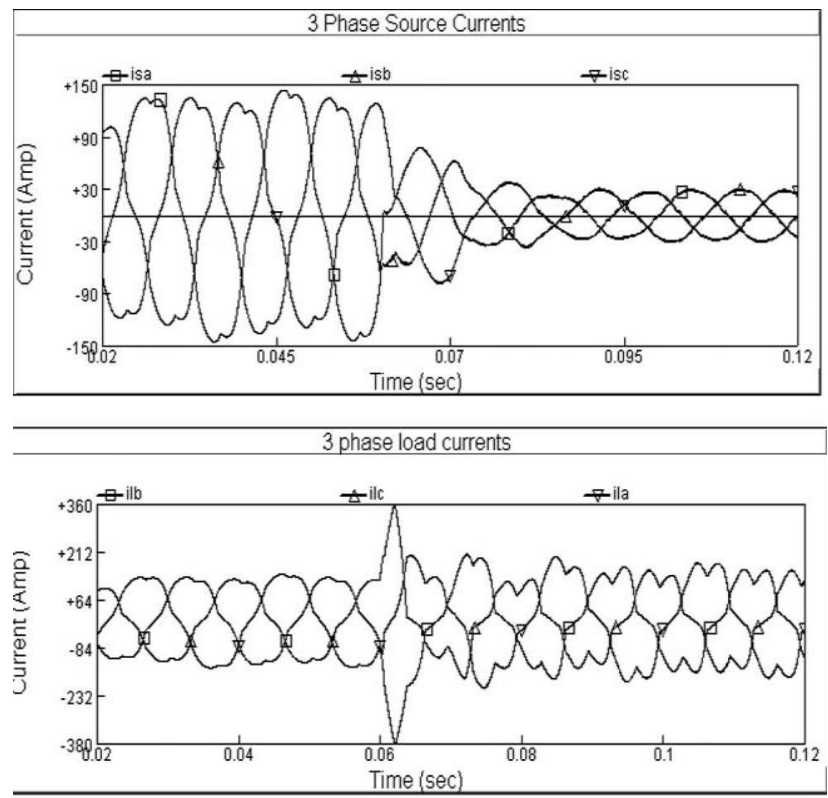

Fig. 6 (b) Three-phase source and load currents before and after the VSI is switched on. 


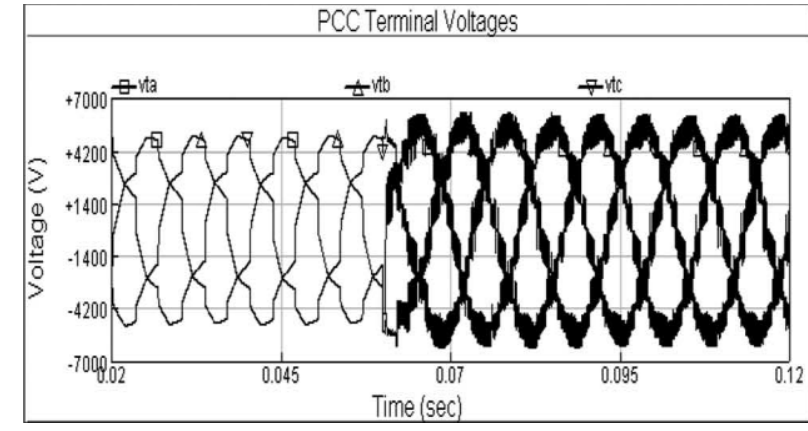

Fig. 6(c) PCC terminal voltages before and after the connection of VSI.

\section{Average Load power and Wind Power}

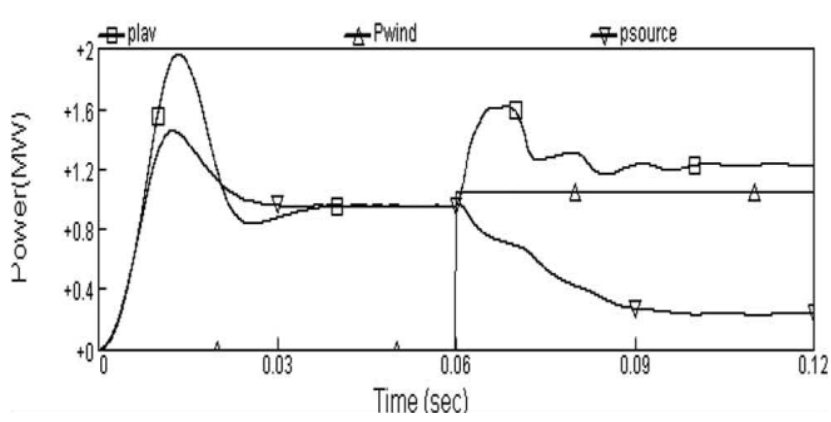

Fig. 6(d) Average load, source, and wind power before and after the connection of VSI

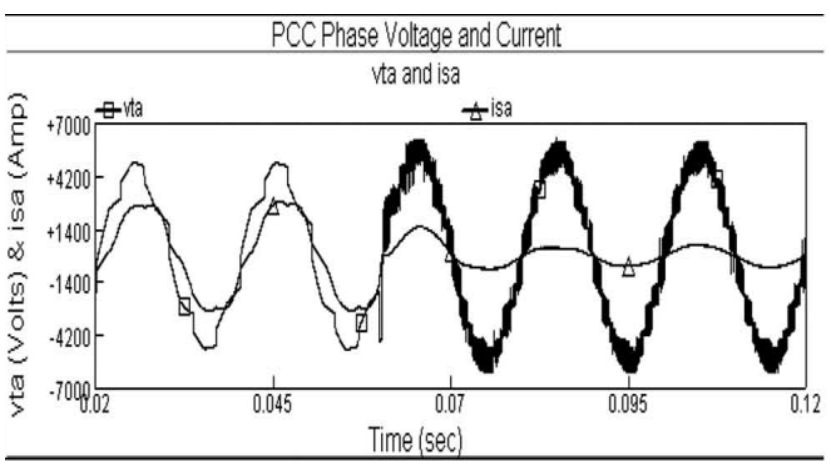

Fig. 6 (e) PCC voltage and source current before and after switching on the VSI for phase A.

Phase A shunt current (VSI) tracking

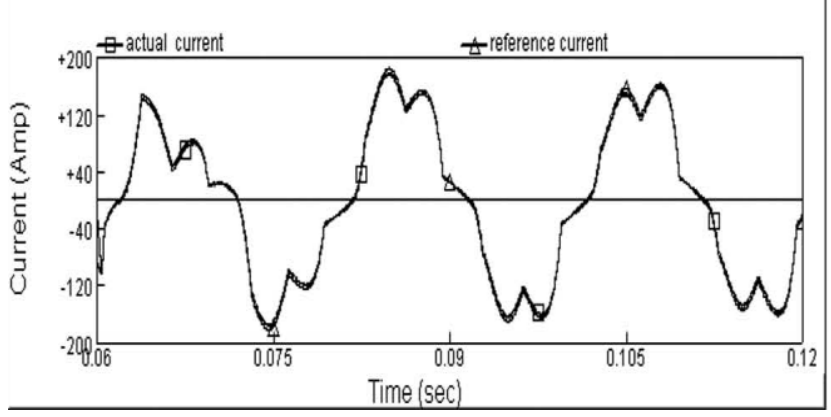

Fig. 6(f)Reference and actual shunt injected current (VSI current tracking).

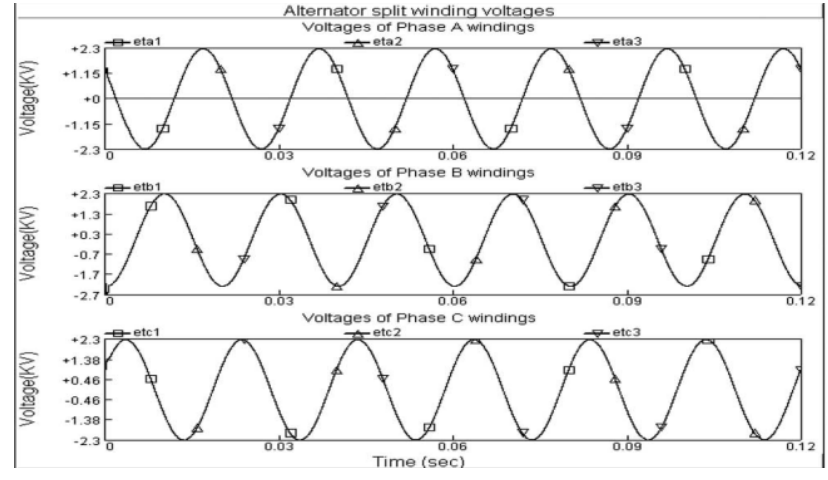

Fig. 6(g) Split-winding ac voltages (three per phase, equal for same phase).

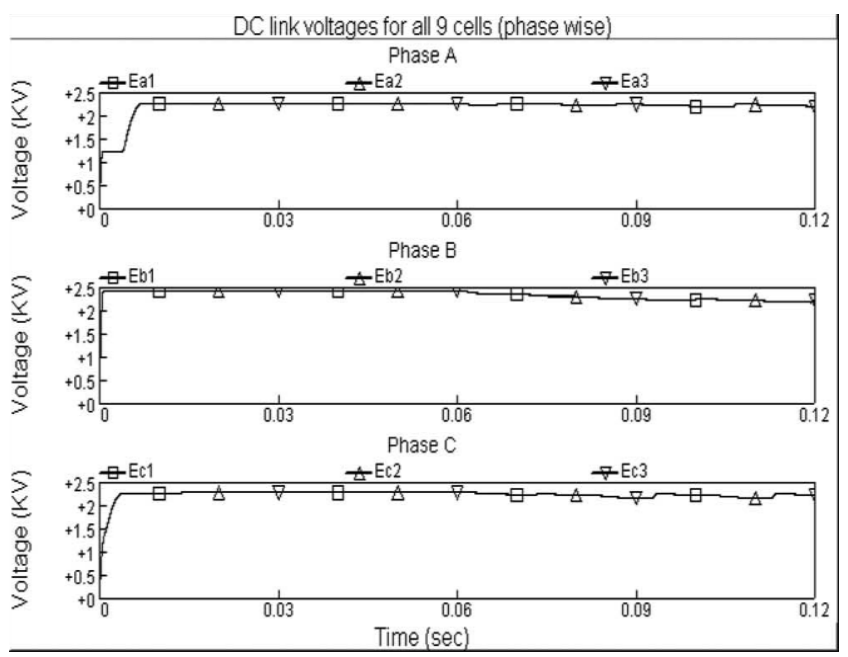

Fig. 6(h) DC-link voltages for all the nine cells (three per phase, equal for same phase).

\section{B. Case 2}

The second simulation starts with the grid supplying a linear unbalanced load while the proposed WECS is operating in parallel with the PCC. The wind power is assumed constant. The dc-link voltage Vdc is controlled to $1.8 \mathrm{kV}$ between $\mathrm{t}=0$ and $0.10 \mathrm{~s}$. At the instant $\mathrm{t}=0.05$ $\mathrm{S}$, a predominantly reactive balanced linear load is connected to the PCC, as shown in Fig. 7 (a). The VSI shows inferior tracking due to increased reference current, i.e., beyond $\mathrm{M}_{\mathrm{i}}=1$, as discussed in Section III-C and seen in Fig. 7 (b). The effect of this can be seen in Fig. 7 (a), where the source currents are no longer balanced and sinusoidal. The dc-link voltage is then increased to $\mathrm{V}_{\mathrm{dc}}=2.2 \mathrm{kV}$ by increasing the reference field excitation voltage at the instant $t=0.10 \mathrm{~s}$, the effect of which is clearly seen in the seven-level cascaded output of the VSI in Fig. 7(c). The tracking performance is now improved. The simulation shows that Vdc of 1.8 $\mathrm{kV}$ is adequate to perform the required compensation at the low load, but when the load is increased at $\mathrm{t}=0.05 \mathrm{~s}$, the compensation becomes inadequate and the source currents get distorted. However, when Vdc is increased, this is sufficient to provide proper load compensation as 
Citation: Sathiyanarayanan, J.S. \& Kumar, A.S. (2013) Power Quality Improvement Wind Energy System Using Cascaded Multilevel Inverter. Int. Journal of Renewable Energy Development, 2(1), 35-43

$\mathrm{P}$ a g e $\mid \mathbf{4 2}$

the closed loop modulation is linear, i.e., $\mathrm{M}_{\mathrm{i}}<1$. This justifies the need to increase Vdc for increased $Q$ in (17). Fig. 7 (a) shows the improvement in the source current waveforms at $\mathrm{t}=0.10 \mathrm{~s}$ with increased Vdc. The THD of source current increases to $4.7 \%$ from $0.26 \%$ initially and improves again to $0.20 \%$ after $\mathrm{Vdc}$ is increased. Fig. 7 (d) shows the phase A PCC voltage and source current, and it can be seen very clearly that the source current is in-phase with the PCC voltage, whereas Fig. 7 (e) shows that the load current is predominantly real up to $\mathrm{t}=0.05 \mathrm{~s}$ and has a much higher reactive component after $\mathrm{t}=0.05 \mathrm{~s}$.

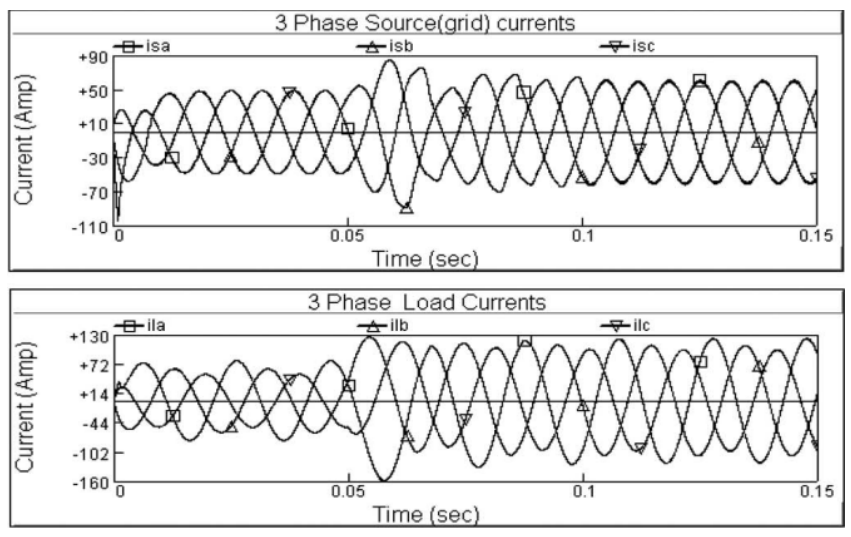

Fig. 7 (a) Three phase source and load currents as dc-link voltage, and load is varied.

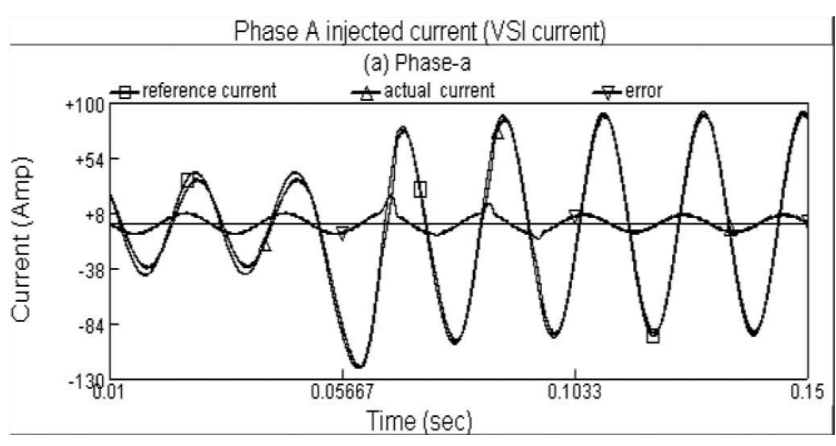

Fig.7 (b) Reference and actual shunt injected current, and tracking error for phase A.

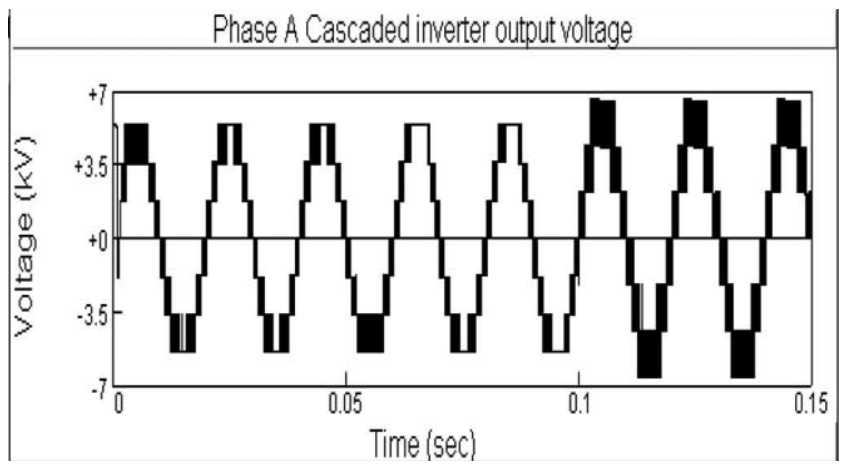

Fig. 7 (c) Cascaded seven-level VSI voltage output.

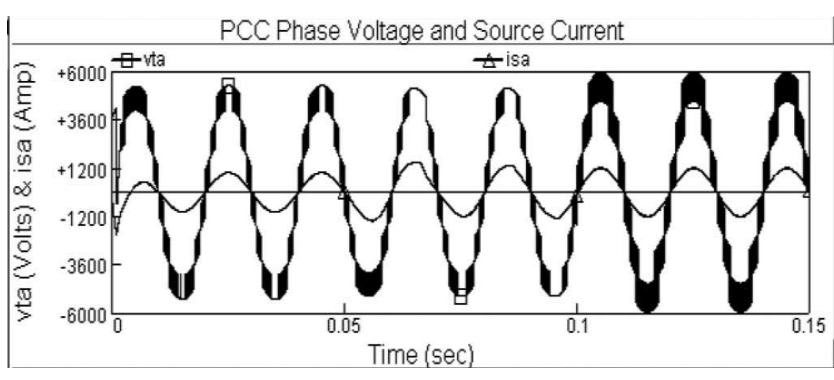

Fig 7 (d) PCC voltage and source current for varying load, and Vdc for phase A.

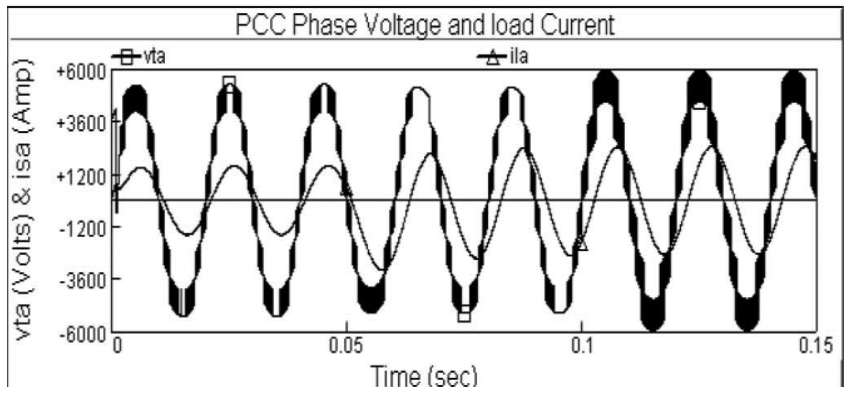

Fig 7 (e) PCC voltage and load current for varying load, and Vdc for phase A.

\section{Conclusions and recommendations}

It has been shown that an SWA with a CHBMLI can be successfully used to interface a large wind turbine to the grid with better power quality at the PCC. The performance of the proposed reference generation scheme is shown to be satisfactory both in terms of real power injection depending upon the available wind power as well as load compensation. The effect of wind and load variations on the distribution of power between the VSI and source has been demonstrated. It is shown that in case the wind power supply is more than the demanded load, the excess power is exported to the grid. The effect of change in the set point of the terminal voltage using field excitation control loop has also been demonstrated. It has been observed that although the VSI is designed for the maximum dc-link voltage, it need not always be operated at the maximum value as the VSI losses depending upon the dc-link voltages. The equal distribution of losses among three CHBs per phase makes it possible to use commonly available switching devices, which will help in reducing the cost of the power electronics component.

\section{References}

ABB Product Catalogue. (2009) Wind Turbine Generators: Reliable Technology for all Turbine Applications, Zurich, Switzerland, Apr. Brekken, T. \& Mohan, N. (2003) A novel doubly-fed induction wind generator control scheme for reactive power control, and torque pulsation compensation under unbalanced grid voltage conditions, in Proc. Power Electron. Spec. Conf. (PESC), 2, 760-764. 
Brekken, T.A., and Mohan, N. (2007) Control of a doubly fed induction wind generator under unbalanced grid voltage conditions, IEEE Trans. Energy Convers., 22 (1), 129-135.

Carrasco, J.M., Franquelo, L.G., Bialasiewicz, J.T., Galv'an, E., Guisado, R.C.P., Prats, M.A.M., Leon, J.I., and Alfonso, N.M. (2006) Powerelectronic systems for the grid integration of renewable energy sources: A survey, IEEE Trans. Ind. Electron., 53 (4), 10021016.

D'iaz-Dorado, E., Carrillo, C., and Cidr'as, J. (2008) Control algorithm for coordinated reactive power compensation in a wind park, IEEE Trans. Energy Convers., 23 (4), 1064-1072

Erickson, R., Angkititrakul, S., Al-Naseem, O., Lujan, G. (2004) Novel power electronics systems for wind energy applications: A report, Nat. Renewable Energy Lab. Subcontractor, Washington, DC, Rep. NREL/SR-500- 33396.

Faulstich, A., Steinke, J.K., and Wittwer, F. (2005) Medium voltage converter for permanent magnet wind power generators up to 5MW, presented at the $11^{\text {th }}$ Eur. Conf. Power Electron. Appl., Dresden, Germany.

Krug, D., Bernet, S., Fazel, S.S., Jalili K., and Malinowski, M. (2007) Comparison of 2.3-kV medium-voltage multilevel converters for industrial mediumvoltage drives, IEEE Trans. Ind. Electron., 54 (6), 2979-2992.
Rodriguez, J., Lai, J.S., and Peng, F.Z. (2002) Multilevel inverters: A survey of topologies, controls, and applications, IEEE Trans. Ind. Electron, 49 (4) 724-738.

Singh, G.K., Yadav, K.B., and Saini, G.K. (2007) A self-excited six phaseinduction generator for standalone renewable energy generation, in Proc. Int. Aegean Conf. Electr. Mach. Power Electron., pp. 690-695.

Slootweg, J.G., De Haan, S.W.H., Polinder, H., and Kling, W.L. (2003) General model for representing variable speed wind turbines in power system dynamics simulations, IEEE Trans. Power Syst, 18 (1), 144- 151.

Steinke, J.K., and Apeldoorn, 0. (2002) Applying the experience of industrial high power converter design to wind power conversion, presented at the World Wind Energy Conf. Exhibit., Berlin, Germany, Paper PD 4-2.

Ullah, N.R., Bhattacharya, K., and Thiringer, T. (2009) Wind farms as reactive power ancillary service providers-Technical, and economic issues, IEEE Trans. Energy Convers., 24 (3), 661-672.

Tenca, P., Rockhill, A.A., and Lipo, T.A. (2007) Wind turbine currentsource converter providing reactive power control, and reduced harmonics, IEEETrans. Ind. Appl., 43 (4), 1050-1060. 